\title{
Research on Seismic Performance of Reinforced Concrete Shear Wall Structure
}

\author{
Zheng Li ${ }^{a}$, Heng Zhou ${ }^{b}$ Li Qin ${ }^{c}$ \\ Hubei University of Arts and Sciences, Xiangyang, Hubei 441053 China \\ alizheng9602@163.com, bzhouheng2001_198@163.com, 'gracieql@emails.bjut.edu.cn
}

\begin{abstract}
Keywords: Shear wall Structure ; dynamic characteristic ; Seismic performance ; shaking-table test

Abstract: The seismic performance of 7-story reinforced concrete shear wall structure is studied, by the shaking table test of the reduced-scaled model. Two test conditions are considered, namely, fixed base and considering soil structure interaction. Under above two conditions, the acceleration time history response of model structure is obtain by test. Based on the time-history response, spectrum analysis is carried out, the dynamic characteristics of model structure are studied. The Finite Element Model of actural structure is established by ANSYS. The dynamic characteristics and time history response of actural structure under seismic action are studied. By comparing the experiment results and numerical analysis results under the fixed-base condition, the rationality of the method of ANSYS finite element numerical analysis is verified.
\end{abstract}

\section{Introduction}

Most domestic and foreign work about the seismic response of structures concentrates on theoretical research and computational analysis. Experimental study on seismic response of shear wall structure, not only can provide necessary parameters for theoretical analysis, but also can obtain abundant experimental data. It can establish the groundwork for calculation analysis and for verifying for the rationality of mechanical model and the calculation method. In recent years, as the shear wall structure is widely used in high-rise buildings, the reasonable seismic analysis method for shear wall structure is also very important. Through the combination of shaking table test and ANSYS numerical analysis, our research focus on the structure dynamic characteristics and seismic performance of a 7-story reinforced concrete shear wall.

\section{Shear wall structure model}

Materials and properties. Compared with steel and concrete, choosing plexiglass as model material can get higher strength and lower elastic modulus, and it is easy to produce. The plexiglass model can produce a larger deformation and poor ductility, and have no obvious signs of damage before. To obtain the physical properties, namely, mass density, elastic modulus and poisson's ratio, we make a test specimen with the same material as the structure model. The tensile test of the specimen results indicates that the average mass density is $\rho_{\mathrm{m}}=1.1875 \mathrm{~g} / \mathrm{cm}^{3}$, the average elastic modulus is $E_{\mathrm{m}}=1012 \mathrm{~N} / \mathrm{mm}^{2}$, poisson's ratio is $v=0.374$.

Model design. The object of test research is a substructure of real shear wall structure, which is made from homogeneous elastic material. The real shear wall structure is 7 -story and storey height $3 \mathrm{~m}$. The plane dimension of the substructure is $6.0 \mathrm{~m} \times 4.0 \mathrm{~m}$, the thickness of the Shear wall is $250 \mathrm{~mm}$. The substructure is extracted as far as possible according to the actual situation, in order to examining the actual seismic response.

The research object in this paper is the seismic response of the structure, so the test is mainly to meet the similar relations among the structure column, beam and plate. Considering bearing capacity of the shaking table and accuracy of the test,We determine the geometric similarity scale of the model is $1 / 25$. The plane dimension of the scaled test model is shown in Fig.1. The test model is shown in Fig.3. According to the theory of dimension analysis, the main similarity relation between the model and the prototype was deduced, witch can be seen in table 1 . 

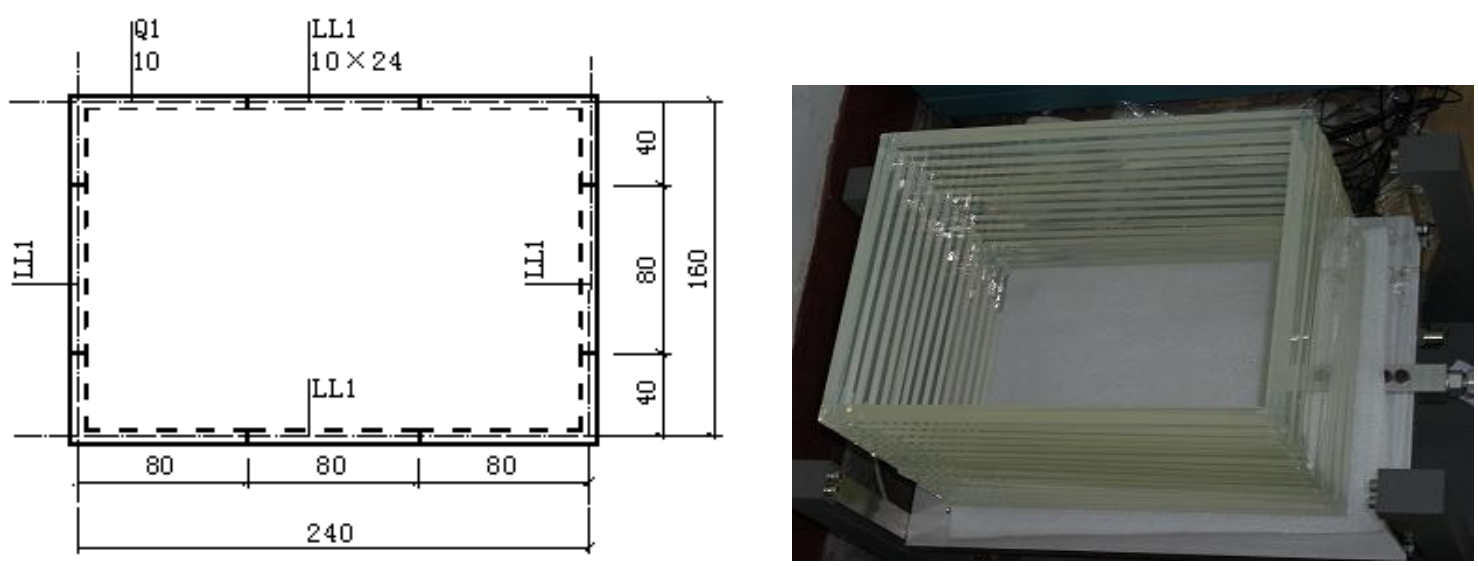

Fig.1 plan view for model of shear wall structure (Units: mm) Fig.2 design for layered shear soil box

Table 1 similarity relation between model and the prototype

\begin{tabular}{cccc}
\hline similarity coefficient & dimension & $\begin{array}{c}\text { Similarity } \\
\text { relation formula }\end{array}$ & $\begin{array}{c}\text { numerical } \\
\text { value }\end{array}$ \\
\hline length & $\mathrm{L}$ & $\mathrm{S}_{\mathrm{L}}$ & 25 \\
Modulus of elasticity & $\mathrm{FL}^{-2}$ & $\mathrm{~S}_{\mathrm{E}}$ & 29.2 \\
density & $\mathrm{FT}^{2} \mathrm{~L}^{-4}$ & $\mathrm{~S}_{\mathrm{\rho}}=\mathrm{S}_{\mathrm{E}} / \mathrm{S}_{\mathrm{L}}$ & 1.168 \\
time & $\mathrm{T}$ & $\mathrm{S}_{\mathrm{t}}=\mathrm{S}_{\mathrm{L}}{ }^{1 / 2}$ & 5 \\
frequency & $\mathrm{T}^{-1}$ & $\mathrm{~S}_{\omega}=\mathrm{S}_{\mathrm{L}}{ }^{-1 / 2}$ & 0.2 \\
mass & $\mathrm{FT}^{2} \mathrm{~L}^{-1}$ & $\mathrm{~S}_{\mathrm{m}}=\mathrm{S}_{\rho} \mathrm{S}_{\mathrm{L}}{ }^{3}$ & 18250 \\
acceleration & $\mathrm{LT}^{-2}$ & $\mathrm{~S}_{\mathrm{a}}$ & 1 \\
\hline
\end{tabular}

Soil box design. In this experiment, a single shear-type shear box is used to design and manufacture the soil box. The soil box is produced by congruent a number of rectangular shear ring made of plexiglass ( the thickness is $8 \mathrm{~mm}$ ) (Fig.2). Frictional resistance between the plexiglass layer is very small, apart from this we apply a lubricant between the layers. Model soil box should reduce the influence of border area to central area, and reduce the model box influence as much as possible.

The calculation of model mass and counterweight. According to the similarity theory, the material density similarity ratio of model and the prototype structure should be $S_{L} / S_{E}=0.843$ theoretically. In fact, the material density similarity ratio of those two is above approaches 0.472 . Therefore, we need to set counterweight to satisfy the similarity relation of density. In this experiment, we build the test model of $850 \mathrm{~mm}$ high including the $10 \mathrm{~mm}$-high base, and the total mass of the model is $7.672 \mathrm{~kg}$, the distributed mass of the model is $6.936 \mathrm{~kg}$, and the total mass of model and counterweight mass under full capacity is $14.607 \mathrm{~kg}$.

\section{Experiment scheme}

The experimental seismic waves. According to the rules in Code for seismic design of buildings (GB50011-2010) [1] , the experiment chooses EL-Centro wave(1940, north-south), Taft wave(1952) and Shanghai artificial wave suiting III-IV field. According to similarity relation, the lasting time of three compressed waves is $10.7 \mathrm{~s}, 10.9 \mathrm{~s}$ and $4.9 \mathrm{~s}$ respectively.

Design of test sensor layout. Piezoelectric accelerometer witch is commonly used for vibration measurement is used in this test[2]. ICP acceleration sensor: frequency response $1 \mathrm{~Hz}-6 \mathrm{KHz}$, acceleration measurement range: $0-10 \mathrm{~g}$; Charge acceleration sensor: frequency response $1 \mathrm{~Hz}-10 \mathrm{KHz}$, sensitivity coefficient: $26.5 \mathrm{Pc} / \mathrm{m} / \mathrm{s}^{2}$. Set ICP acceleration sensors at the middle of each floor and the bottom of shear walls; Set one charge accelerometer on the shaking table, in order to control the vibration acceleration of the shaking table, as Fig.3. The dynamic strain gauge was vertically posted on the upper, middle and lower sections of the wall fulcrum on each structural layers[3]. 


\section{Analysis on test results of shear wall model with rigid foundation}

The dynamic characteristics of the model. Before the time-history analysis on model structure, the dynamic characteristic analysis under elastic state is carried out first to test the reliability of the model initially, and adjust the plexiglass models. Soil box in test considering soil-structure interaction is shown in fig.4.
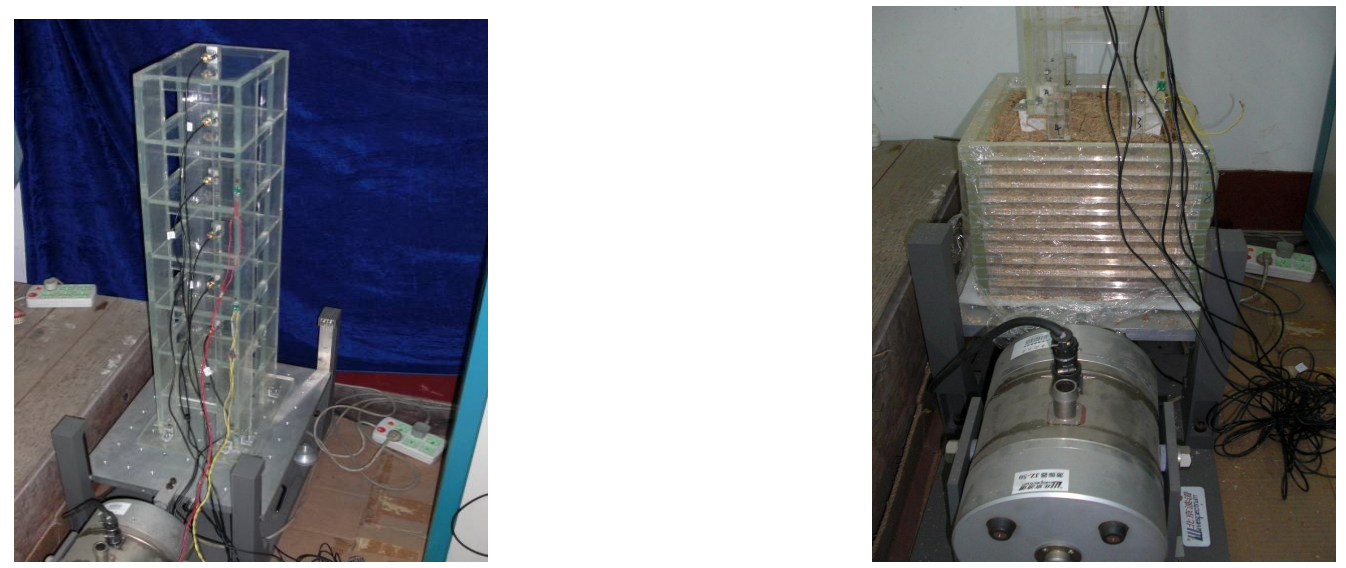

Fig. 3 position of accelerometers and dynamic strain gauges Fig.4 soil box in test considering interaction between soil and structure

After checking the model, the self-vibration frequency of the model is obtained (shown as table 2). According to table 2, the self-vibration frequency obtained by test is consistent with that calculated by ANSYS. The y-coordinate stands for the longer edge, and the vertical edge (the longer edge) is higher in rigidity, and has a higher self-vibration frequency. The ANSYS calculation result of model structure condition along the $\mathrm{x}$-coordinate is in fig.5.

Tab.2 first three frequencies of the model structure

\begin{tabular}{ccccc}
\hline dynamic characteristics & $\begin{array}{c}\text { the first } \\
\text { mode }\end{array}$ & $\begin{array}{c}\text { the second } \\
\text { mode }\end{array}$ & the third mode \\
\hline & $\begin{array}{c}\text { frequency } \\
\text { of } \\
\text { calculation } \\
/ \mathrm{Hz}\end{array}$ & 17.768 & 25.196 & 66.720 \\
\cline { 2 - 5 } $\begin{array}{c}\text { White noise } \\
\text { test of elastic } \\
\text { state }\end{array}$ & $\begin{array}{c}\text { frequency } \\
\text { of } \\
\text { experiment } \\
/ \mathrm{Hz}\end{array}$ & 18.438 & 24.432 & 83.675 \\
\cline { 2 - 6 } & $\begin{array}{c}\text { relative } \\
\text { error }\end{array}$ & $3.77 \%$ & $3.03 \%$ & $25.41 \%$ \\
\cline { 2 - 6 } & $\begin{array}{c}\text { mode of } \\
\text { vibration }\end{array}$ & $\begin{array}{c}\text { translation in } \\
\mathrm{X} \text { direction }\end{array}$ & $\begin{array}{c}\text { translation in } \\
\text { Y direction }\end{array}$ & $\begin{array}{c}\text { translation in } \mathrm{X} \\
\text { direction }\end{array}$ \\
\hline
\end{tabular}




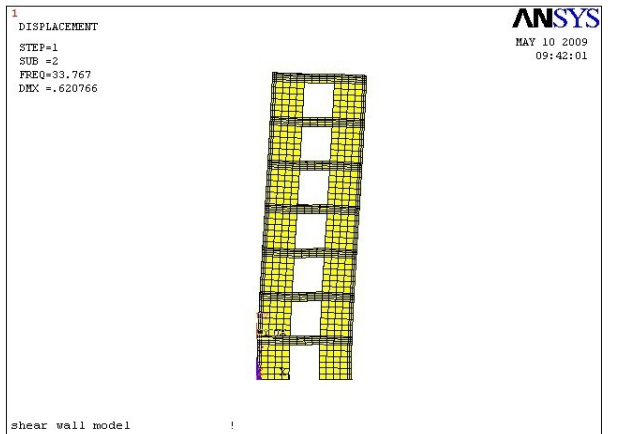

Fig.(a) the first mode in $\mathrm{X}$ direction

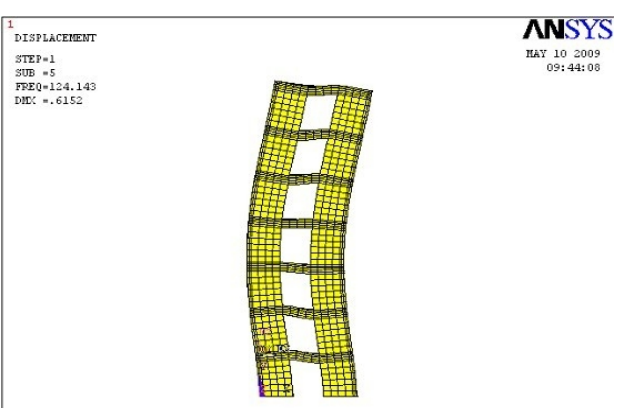

Fig.(b) the second mode in $\mathrm{X}$ direction

Fig. 5 modes analyzed by ANSYS program

The acceleration response of models. The acceleration response of model structure under the three seismic waves is shown in fig.6 and fig.7. Through anslysis the accelearion curves, the conclusions can be obtaioned : (1) the peak acceleration is amplified as the floor increasing, and the maximum peak acceleration shows up at the top of the structure. Structure of lateral stiffness is uniform along the vertical edge. (2) Each wave was input to the table with similar acceleration, due to the differences of spectrum characteristics, the acceleration response of model varies in degrees. TAFT wave has a greater impact on structure dynamic response. Shanghai artificial wave has the strongest impact at the bottom, the weakest at the top.

In order to compare the experimental results with the theoretical analysis results, the acceleration time history of test and theoretical analysis are compared (shown in figure 8). From Fig.8, it can be concluded that experimental results is almost consistent with the theoretical ones.

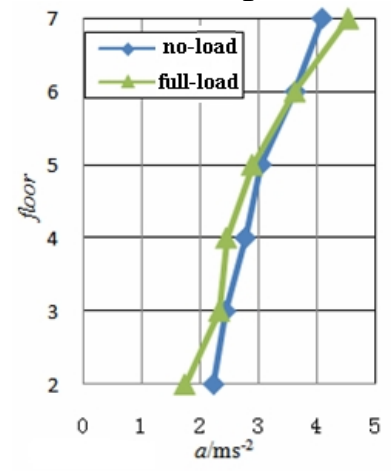

Fig.(a) wave of EL-CENTRO

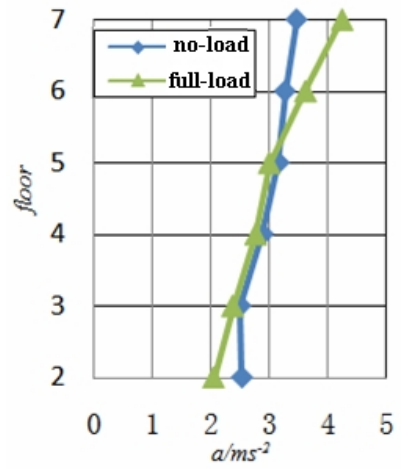

Fig.(b) wave of TAFT

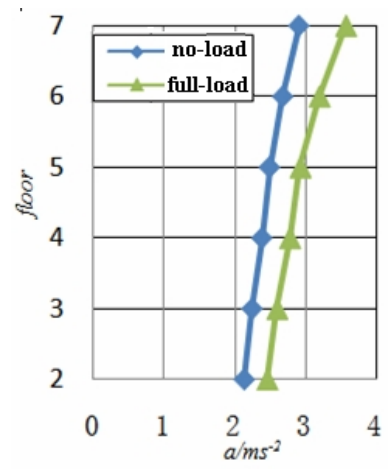

Fig.(c) artificial wave of Shanghai Fig. 6 acceleration responses in $\mathrm{X}$ direction under 8 degree basic seismic

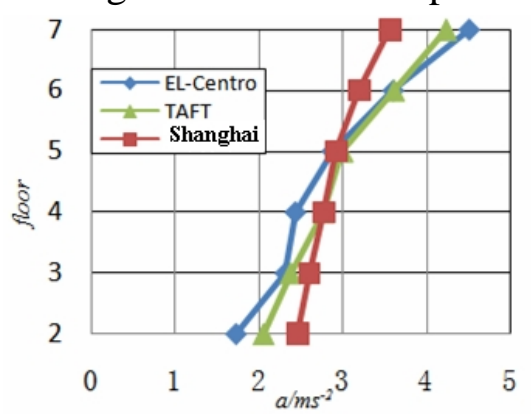

Fig.(a) acceleration responses under three seismic waves

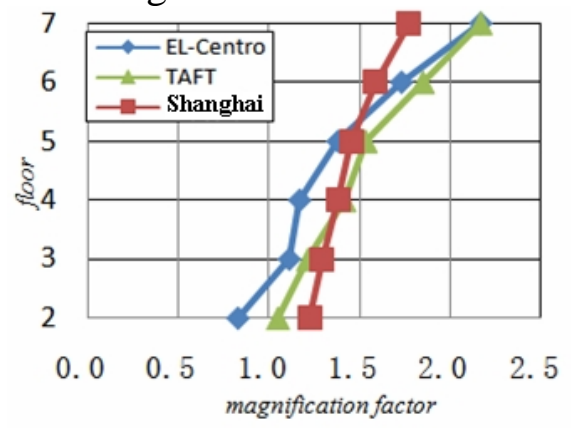

Fig.(b) magnification factor of acceleration responses under three seismic waves

Fig.7 acceleration responses and its magnification factor in $\mathrm{X}$ direction under three seismic waves of 8 degre

The displacement response of model. According to the horizontal displacement response of models (Fig.9). The conclusions can be obtained: (1) The displacement response of models is not obvious, which is consistent with the facts that the model is completely under the elastic condition. 
The displacement is basically bending type. (2) As the seismic intensity goes high, the displacement response of model grows stronger, which indicates that the displacement response of model is easy to get effected by the seismic intensity. (3) This model doesn't have the weak floor, according to which we can infer that the prototype of shear wall structure is uniform in design.

Tab.3 shows interstory drift and story drift angle of the model under TAFT wave. We can find out that, when the TAFT wave was input, the interstory drift and story drift angle of the model are all very small, even the maximum is only $1 / 1980$, much smaller than the limit of $1 / 1000$ in code for seismic design of buildings.

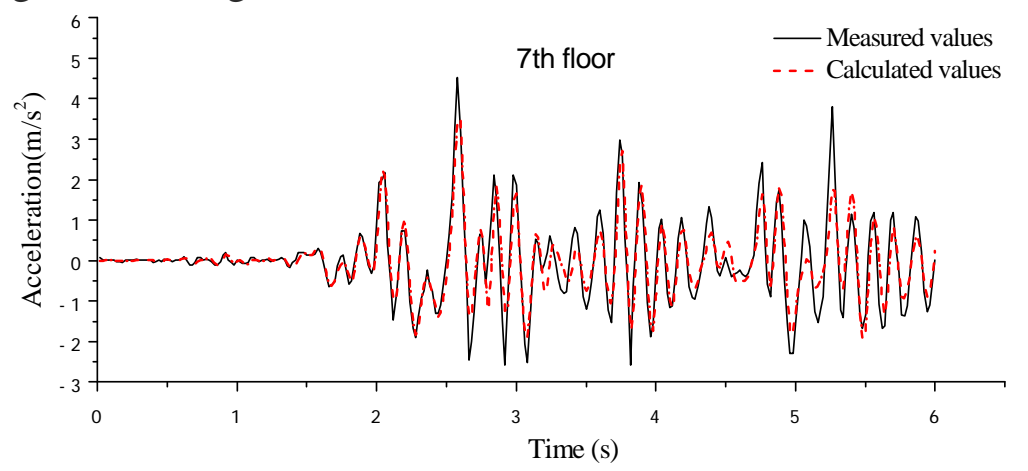

Fig. 8 history value comparison of acceleration responses between test and model displacement under

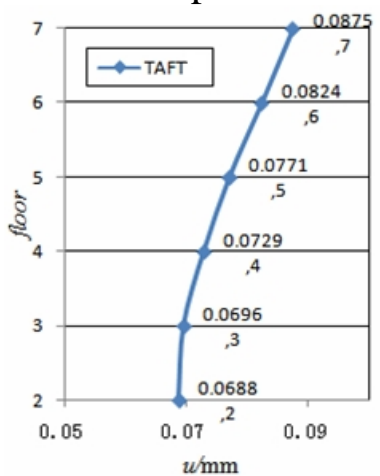

Fig.9 peak value of theoretical results in 7 th floor under 8 degree basic seismic 7 degree frequent seismic

The Strain response of model. Do the strain at the middle of the shear wall is measured under three seismic waves with peak corresponding to 9 degrees earthquake. The result is shown in Tab.4. According to Tab. 4, the following conclusion can be obtained: under the three seismic waves, the shear wall structure present bending type deformation and the greatest deformation appeared at the bottom. The greatest stress appeared at the bottom of the shear wall, which makes the bottom of the shear wall is the weakest part.

The inter-storey shear of model. Assume that the mass of the model concentrates at the height of floor, that is, candied fruit series model. The absolute acceleration response can be obtained by accelerometer placed at the floor of the building, then the inertial force of the mass concentrated place of model floor can be calculated[3]. The shear of each floor of the model can be calculated by the equation below:

$$
r_{k}\left(t_{i}\right)=\sum_{k}^{n} m_{k}\left(t_{i}\right)
$$

The subscript " $k$ " in equation 1 stand for the floor number, $\left(t_{i}\right)$ stands for the absolute acceleration of floor " $k$ " at time " $t_{i}$ ", $m_{k}$ stands for the mass of floor " $k$ ".

By taking the above floor and the below floor of the test point as one particle, approximately obtain the inter-storey shear distribution of the model. According to the similitude ratio, can get the inter-storey shear distribution of the prototype. 
Tab.3 inter-story displacement and its rotation under varied degree seismic of TAFT wave

\begin{tabular}{|c|c|c|c|c|c|c|c|}
\hline intensity & $\begin{array}{c}\text { working } \\
\text { conditio } \\
n\end{array}$ & & $\begin{array}{l}\text { the } \\
\text { third } \\
\text { floor }\end{array}$ & $\begin{array}{l}\text { the } \\
\text { fourth } \\
\text { floor }\end{array}$ & $\begin{array}{l}\text { the fifth } \\
\text { floor }\end{array}$ & $\begin{array}{l}\text { the } \\
\text { sixth } \\
\text { floor }\end{array}$ & $\begin{array}{c}\text { the } \\
\text { seventh } \\
\text { floor }\end{array}$ \\
\hline \multirow{2}{*}{$\begin{array}{l}7 \text { degree basic } \\
\text { seismic }\end{array}$} & \multirow{2}{*}{28} & $\begin{array}{l}\text { interstory } \\
\text { drift }\end{array}$ & 0.0203 & 0.0247 & 0.0122 & 0.0171 & 0.0052 \\
\hline & & $\begin{array}{l}\text { story drift } \\
\text { angle }\end{array}$ & $1 / 5911$ & $1 / 4858$ & $1 / 9836$ & $1 / 7018$ & $1 / 23077$ \\
\hline \multirow{2}{*}{$\begin{array}{l}8 \text { degree basic } \\
\text { seismic }\end{array}$} & \multirow{2}{*}{30} & $\begin{array}{l}\text { interstory } \\
\text { drift }\end{array}$ & 0.0417 & 0.0340 & 0.0129 & 0.0246 & 0.0084 \\
\hline & & $\begin{array}{l}\text { story drift } \\
\text { angle }\end{array}$ & $1 / 2878$ & $1 / 3529$ & $1 / 9302$ & $1 / 4878$ & $1 / 14286$ \\
\hline \multirow{2}{*}{$\begin{array}{l}9 \text { degree basic } \\
\text { seismic }\end{array}$} & \multirow{2}{*}{32} & $\begin{array}{l}\text { interstory } \\
\text { drift }\end{array}$ & 0.0498 & 0.0606 & 0.0533 & 0.0339 & 0.0307 \\
\hline & & $\begin{array}{l}\text { story drift } \\
\text { angle }\end{array}$ & $1 / 2410$ & $1 / 1980$ & $1 / 2251$ & $1 / 3540$ & $1 / 3909$ \\
\hline
\end{tabular}

Tab.4 strain response in middle of lowest column under three kinds of 9 degree seldom seismic

\begin{tabular}{cccc}
\hline floor & EL-Centro wave & TAFT wave & $\begin{array}{c}\text { artificial wave of } \\
\text { Shanghai }\end{array}$ \\
\hline 6 & 4.88 & 6.80 & 7.87 \\
4 & 5.91 & 5.89 & 8.01 \\
1 & 30.32 & 26.32 & 33.34 \\
\hline
\end{tabular}

\section{Analysis towards experiment results considering soil- structural interaction [4-5]}

Dynamic characteristics of model. According to Tab.5, due to the influence of soil, the seismic wave from the table has reduced, that is, the seismic wave input to the table has a great influence toward the upper structure, the frequencies in two direction have reduced $71.9 \%$ and $76.3 \%$ respectively, the direction in which lateral stiffness is higher has a greater reduction on frequency, that is $76.3 \%$.

Tab.5 first two frequencies comparison without counterweight

\begin{tabular}{|c|c|c|c|}
\hline $\begin{array}{l}\text { the frequency } \\
\text { order }\end{array}$ & test type & frequency $/ \mathrm{Hz}$ & $\begin{array}{l}\text { vibration mode } \\
\text { shape }\end{array}$ \\
\hline \multirow{3}{*}{$\begin{array}{l}\text { first-order } \\
\text { frequency }\end{array}$} & rigid foundation & 24.269 & \multirow{3}{*}{$\begin{array}{c}\text { translation in } \mathrm{X} \\
\text { direction }\end{array}$} \\
\hline & interreaction & 6.818 & \\
\hline & $\begin{array}{c}\text { frequency step } \\
\text { down }\end{array}$ & $71.9 \%$ & \\
\hline \multirow{3}{*}{$\begin{array}{l}\text { second-order } \\
\text { frequency }\end{array}$} & rigid foundation & 32.386 & \multirow{3}{*}{$\begin{array}{c}\text { translation in } Y \\
\text { direction }\end{array}$} \\
\hline & interreaction & 7.67 & \\
\hline & $\begin{array}{l}\text { frequency step } \\
\text { down }\end{array}$ & $76.3 \%$ & \\
\hline
\end{tabular}

Acceleration response considering soil-structure interaction. The structure response considering and without considering soil-structure interaction is compared in Fig. 10. The following conclusion can be obtained: (1) The peak acceleration on each floor reduces under earthquake with various seismic intensity under soil-structure interference. (2) Under earthquakes with different seismic intensity, the peak acceleration appears at the top floor. (3) Although the model is always under the elastic state, due to the dynamic interaction of soil- structure, the relationship between the seismic response of structure and the seismic intensity is not linear, which reflects the influence of soil-structure interaction. 


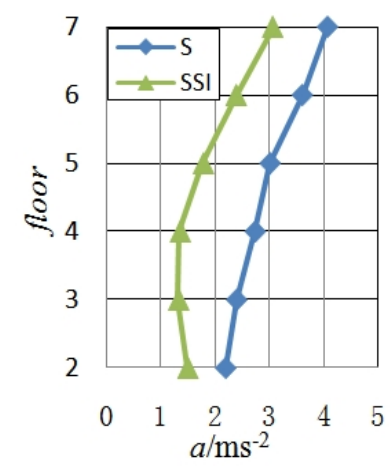

Fig.(a) wave of EL-CENTRO

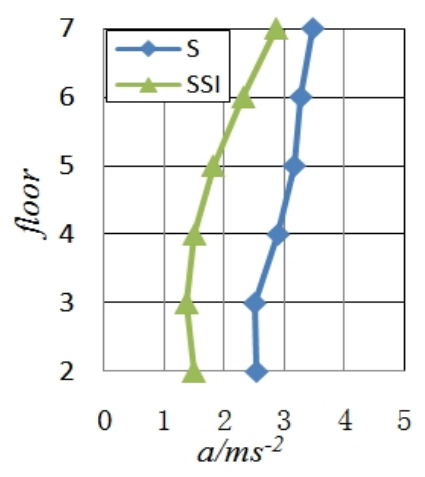

Fig.(b) wave of TAFT

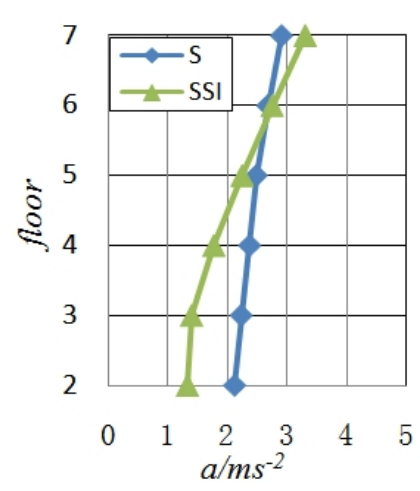

Fig.(c) artificial wave of Shanghai

Fig.10 peak value of acceleration response under 8 degree basic seismic

\section{Conclusions}

The results of model table-test is almost consistent with that of the theoretical analysis, which indicates that shaking table test is reliable, validate the reasonability of ANSYS analysis at the same time. The research work in this paper provides definite reference for elasto-plastic time history analysis of real shear wall structure. The detailed conclusions are:

(1) The long edge of shear wall structure has the higher self-vibration frequency, that is, the higher the lateral stiffness is, the higher the self-vibration frequency would be.

(2) This model structure doesn't have the obvious soft layer, from which we can infer that design of reinforced concrete shear wall structure is reasonable.

(3) The self-vibration frequency of structure considering soil structure interaction reduces $71.9 \%$ and $76.3 \%$ in two directions respectively compared to that of structure of fixed base. The soil structure interaction has more impact on the direction in which the lateral stiffness is greater.

(4) The peak acceleration and peak magnification factors of each floor all decreases when considering soil-structure interference, the dynamic response peak and strength of seismic vibration are not in linear relationship.

\section{Acknowledgements}

This study was in part supported by grants form the Nature Science Foundation of Hubei Province, China (2014 CFB638) and the National Natural Science Foundation of China (51208188)

\section{References}

[1] National standard of the People's Republic of China. (GB50011-2010) Code for seismic design of buildings. Beijing: China Architecture and Building Press, 2010. (in Chinese).

[2] Beijing Wavespectrum Company. Instructions of VibSQK for shaking table system WS-Z50. Beijing, 2007. (in Chinese).

[3] Shouping Shang, Zhihui Zhu, Wenge Tu,etc. Journal of Hunan University(Natural Sciences), 2004, 31(5):71 76. (in Chinese).

[4] Woo-Jung Chung, Chung-Bang Yun, Nam-Sik Kim, Ju-Won Seo. Shaking table and pseudo dynamic tests for the evaluation of the seismic performance of base-isolated structures. Engineering Structures, 1999; 21:365-379.

[5] Peizhen Li; Xilin Lv. Earthquake Engineering and Engineering Vibration, 2004,6(3):130 138. (in Chinese).

[6] Xilin Lu, Yun Zou, Wensheng Lu and Bin Zhao. Shaking table model test on Shanghai World Financial Center Tower. Earthquake Engineering and Structural Dynamics, 2007; 36:439-457 